Revista da Rede Brasileira de História da Geografia e Geografia Histórica

\title{
Naturaleza y tradición en los orígenes de la
}

Geografía argentina

El proyecto disciplinario de Elina Correa Morales

\section{Perla Zusman}

\section{(2) OpenEdition}

\section{Journals}

Edición electrónica

URL: https://journals.openedition.org/terrabrasilis/335

DOI: 10.4000/terrabrasilis.335

ISSN: 2316-7793

Editor

Rede Brasileira de História da Geografia e Geografia Histórica

\section{Edición impresa}

Fecha de publicación: 1 enero 2001

ISSN: 1519-1265

\section{Referencia electrónica}

Perla Zusman, «Naturaleza y tradición en los orígenes de la Geografía argentina», Terra Brasilis [En línea], 3 | 2001, Publicado el 05 noviembre 2012, consultado el 05 diciembre 2022. URL: http:// journals.openedition.org/terrabrasilis/335 ; DOI: https://doi.org/10.4000/terrabrasilis.335

Este documento fue generado automáticamente el 5 diciembre 2022.

All rights reserved 


\title{
Naturaleza y tradición en los orígenes de la Geografía argentina
}

\author{
El proyecto disciplinario de Elina Correa Morales
}

\section{Perla Zusman}

1 Hacia 1900, en Argentina, la sindicalización y organización de los inmigrantes despertaron la preocupación de las elites y sectores intelectuales que percibían en este proceso una amenaza a su mantenimiento del poder político. Este proceso estaba poniendo en juego los valores y las formas de socialización por ellas establecidas.

2 Frente a esta situación, una de las reacciones políticas fue el desarrollo de acciones de afirmación nacional desde las escuelas destinadas a asimilar tanto al inmigrante como al indígena a los valores de las elites gobernantes.

3 En este contexto, Svampa (1994) distingue dos vertientes que fundamentaron los programas educativos de la época. La primera perspectiva se construye sobre la base del pensamiento positivista y cientificista. Continuadora de la línea de reflexión que fundamentó el proyecto de formación nacional estatal consustanciado entre $1860 \mathrm{y}$ 1880 , la preocupación de los intelectuales y políticos que se inscriben en esta visión sigue desarrollándose en torno a cuestiones como el progreso y la necesidad europeizar al país a partir de la inmigración masiva. La asimilación o extinción de los nativos tanto criollos como indígenas -considerados étnicamente inferiores continúa presentándose como una prioridad política. La figura del inmigrante, desde esta visión, todavía posee connotaciones positivas.

4 La segunda vertiente encuentra sus fuentes en el espiritualismo filosófico (Weibrode, K., College, B., 1991) y elabora un pensamiento esencialista de la Nación. En esta nueva "invención de la nación" la figura del inmigrante, hasta entonces representante de la “civilización", "aliado económico" de los sectores dirigentes, es reemplazada por una imagen donde este resulta una amenaza a la disolución de los valores nacionales. En este marco se revalorizan el interior, las tradiciones, la figura del nativo, del gaucho y, más aún, las raíces hispánicas. 
5 La aproximación a la trayectoria intelectual e institucional de Elina Correa de Morales, deja traslucir la influencia en sus concepciones de ambas vertientes. Por un lado la influencia espiritualista, la lleva a perseguir la preservación de la diversidad cultural y geográfica pasadas como componente que contribuiría a la construcción, en términos de Benedict Anderson, de la comunidad imaginada argentina del 1900. Por otro, la vertiente positivista, la orienta en la búsqueda de a partir de otorgar un contenido científico de corte naturalista a todo aquel conocimiento, particularmente al considerado bajo el rótulo disciplinario de geografía, que contribuiría a la socialización de los inmigrantes y nativos en los valores nacionales.

6 Este proyecto científico-cultural tiene también dos pilares. Uno de ellos de carácter académico orientado a la que sean científicos nacionales y no extranjeros los que realicen los estudios que den cuenta de la diversidad cultural y geográfica de la Argentina. Esto quiere decir que, ella se distancia de las propuestas civilizatorias que suponían situar a la Argentina desde el punto de vista científico en los marcos epistemológicos europeos a partir la comulgación con cierto cosmopolitismo.

El otro pilar se asentaba sobre la enseñanza y suponía la transmisión de los conocimientos producidos a nivel académico en el ámbito escolar. A través de su pasaje por la Escuela Normal ella internalizó los objetivos de disciplinamiento y control social que desde el gobierno nacional se le había atribuido a la socialización de los sujetos en este centro educativo, formador de maestros de escuela primaria (Puigróss, 1990: 109). Elina Correa Morales compartió con los egresados normalistas el sentimiento de estar cumpliendo una "misión civilizador", de ser "apostóles de la instrucción primaria", "destinados" a ocupar cargos directivos dentro de las organizaciones educativas de todo el país (Roig, 1964: 64-65). Su papel de asesora en las reformas de planes de estudios de la escuela secundaria en el área de Geografía, le permitió completar su papel "misional", ya que fue desde allí donde se difundió el proyecto nacionalista y cientificista para la enseñanza de la Geografía.

Entre su proyecto académico y de enseñanza, Elina Correa Morales, encontró un elemento articulador. Este fue la Sociedad Argentina de Estudios Geográficos (1922), conocida más comúnmente como GAEA. ${ }^{1}$ Concebida como una sociedad de científicos interesados en la promoción de un conocimiento considerado como geográfico, GAEA nucleó a todos aquellos interesados en la producción y el debate del conocimiento en torno a la información que estaba produciéndose respecto a las características físicas, económicas y etnográficas del territorio argentino, y que, a través de sus acciones públicas, buscaban difundir su propuesta disciplinaria, en el ámbito de la enseñanza. Se trataba de un proyecto epistemológico caratulado de científico frente a las propuestas previas, rotuladas como enumerativas, memorísticas $\mathrm{y}$, por lo tanto, considerada desde los miembros de GAEA como no científicas.

Conocer la trayectoria y la obra de Elina Correa Morales, en el contexto de emergencia de las propuestas nacionalistas, resulta una vía de entrada, entre otras posibles, a las implicaciones que la difusión de este ambiente político tuvo en el ambiente científico, por un lado, y, por el otro, en la enseñanza de una disciplina a la que se le atribuyó potencialidades nacionalizadoras.

10 Un abordaje de estas características busca también comprender el proceso de gestación y perpetuación de una perspectiva naturalista, deliberadamente objetiva y apolítica de la realidad social, vehiculizada por la propuesta epistemológica en la que se apoyaba el conocimiento considerado geográfico. 


\section{I - Entre la cultura y las ciencias: Elina González Acha de Correa Morales}

11 Elina González Acha de Correa Morales (1861-1942) nació en el marco de una familia patricia ilustrada, un contexto que actuó como estímulo para su desarrollo intelectual. Realizó sus estudios de magisterio en la Escuela Normal $\mathrm{N}^{\circ} 1$ de Buenos Aires. Su acercamiento al botánico darwinista Eduardo Holmberg, profesor de ciencias naturales en dicho centro educativo la aproximó a ciertas vertientes del mundo científico y artístico que otorgaban importancia a que la actividad científica desarrollada en el país estuviese a cargo de especialistas argentinos. Correa Morales estaba cursando el tercer año cuando se hizo cargo de las clases de botánica de la Escuela de Aplicación del Normal. La aproximación a Holmberg también le permitió entrar en contacto con los miembros de la Sociedad de Ciencias Físicas y Naturales (Physis) y participar de las actividades del Museo de Ciencias Naturales de Buenos Aires. El desarrollo de su perfil académico se consolidó mediante su inserción en el medio académico internacional, a través de presentación de ponencias a Congresos (Ginebra 1908, Río de Janeiro1910, Buenos Aires 1910) y, particularmente, con su papel protagónico en la fundación de la Sociedad Argentina de Estudios Geográficos.

Sus intereses académicos fueron complementarios con su militancia en el feminismo liberal. Ella participó en todos aquellos ámbitos que promovieran el estímulo de la valorización intelectual de la mujer en una época en que su participación científicoacadémica no era vista con buenos ojos (Barrancos, 2000). De hecho, Elina González Acha experimentó este rechazo cuando solicitó su incorporación a las actividades del Instituto Geográfico Argentino (IGA, 1889: 19). Esta Sociedad Geográfica, fundada por Estanislao Zeballos en 1879, recién aceptó su incorporación en los inicios del siglo XX, período en que su nombre comienza a aparecer en el listado de sus miembros y que coincide también con la publicación de dos de sus trabajos en el Boletín de esta institución (Correa Morales, 1904, 1909). Elina González Acha formaba parte, junto con la enfermera Cecilia Grierson, de uno de los organismos más activos para la época en temas de reivindicación de los derechos de la mujer como fue Consejo Nacional de Mujeres, filial del Consejo londinense "que respondía a las apreciaciones positivistas tan en boga durante el primer tercio de principios de siglo" (Apolonia del Brutto, 1998). Correa Morales y Grierson participaban también de la Escuela Técnica del Hogar, y de la Biblioteca de Mujeres (Fundación Francisco Aparicio, 1973). Sus intereses feministas y académicos explican también el hecho de que fuera miembro correspondiente de la Sociedad de Mujeres Geógrafas de Washington (Casal, 1943: 143). Esta Sociedad había sido fundada en 1925 con el objetivo de agrupar a las mujeres que desarrollaban tareas de exploración e investigación territorial en un contexto en que ellas no podían participar en las asociaciones formadas por hombres (Society of Woman Geographers, 2001).

13 En síntesis, Elina Correa Morales puede ser caracterizada como maestra de escuela normal, como académica y como defensora de la actuación de la mujer en los ámbitos científicos y en la vida cotidiana. Estos tres aspectos resumen su trayectoria pública y sirven también para aproximarse a su producción intelectual.

La obra de Correa Morales está constituida por veintiséis trabajos. Dentro de los estudios estrictamente académicos podemos distinguir: quince investigaciones 
publicadas en instituciones geográficas como fueron el Instituto Geográfico Argentino y la Sociedad de Estudios Geográficos y seis presentaciones a congresos. De caratular esta producción podríamos decir que de estos veintiún trabajos, diecinueve están próximos a la Geografía y los dos restantes al campo de la antropología. La mayor parte de las investigaciones geográficas pueden ser consideradas como trabajos de geografía histórica, historia de la geografía, enseñanza de la Geografía y Geografía física argentina. Los cinco trabajos restantes no son propiamente trabajos de investigación sino obras didácticas; cuatro de ellas son libros de lectura para colegio primario y uno es un libro de enseñanza de la Geografía.

Una primera aproximación cualitativa a su producción, nos permite identificar la preocupación de Correa Morales por dotar de cientificidad a sus propuestas académicas. Dos estrategias le garantizan la inserción de sus producciones en el marco epistemológico vigente en Argentina entre finales del siglo XVIII y mediados del XX. En principio es la historicidad de los procesos, a veces, pasada a los términos del evolucionismo darwiniano, quien garantiza tal cientificidad, particularmente en los trabajos de tipo antropológico; en otros, es la adscripción a una tradición presentada a través de una narrativa de la historia disciplinaria y el rescate de un objeto y método, particularmente en los estudios geográficos los que le otorgan tal legitimidad epistemológica. Quizás sean estas estrategias de legitimación científica un camino posible para aproximarnos a los intereses temáticos de la autora.

Sin duda, un análisis como el que nos proponemos nos lleva voluntariamente a considerar al autor, como principio de agrupación del discurso, como unidad y origen de sus significaciones, como foco de coherencia (Foucault, 1999: 30), ya que es a través del análisis de dicha producción que pretendemos conocer su proyecto disciplinar, la forma en que Correa Morales entendió los vínculos entre producción científica y producción cultural; entre producción académica y la transposición de los contenidos elaborados en este nivel a los ámbitos de enseñanza y, por último, la repercusión institucional de su propuesta disciplinaria para la Geografía.

\section{I.1 - La relación pasado-presente y la incorporación de la diversidad étnica a la invención de la tradición}

17 El estudio de la relación pasado-presente desde un punto de vista antropológico se aprecia en su ponencia Facultades que han contribuido a desarrollar el ejercicio de la caza entre los primitivos presentada en el Congreso de Americanistas realizado en 1910 en Buenos Aires. En esta ponencia, ella analiza la influencia de una actividad económicocultural como es la caza en la evolución hominídea americana (términos propios del paleontólogo Florentino Ameghino) y en el desarrollo físico y cultural de las sociedades que ella denomina primitivas .

18 En este sentido, Correa Morales sigue al arqueólogo evolucionista francés Gabriel Mortillet quien destaca la influencia de las técnicas en la evolución humana:

Las armas más que ninguna otra manifestación de la industria, nos dan á conocer cuánta era la inaptitud de la especie humana en sus primeros pasos por la tierra; ellas también las que por su perfeccionamiento y variación nos llevarán etapa por etapa á conocer gran parte del desenvolvimiento de su cultura (Correa Morales, 1910a: 547). 
19 Para E. Correa Morales en torno a la actividad de la caza se construyeron ciertos tipos de actitudes como la asociación y la solidaridad, o también ciertos rituales como fiestas en honor a los cazadores o a ciertos dioses. Esta autora también presenta las distintas formas de practicarla y sus efectos en diversas sociedades aborígenes sudamericanas. Para realizar estas reflexiones Correa Morales toma como punto de partida los trabajos etnográficos de especialistas que habrían trabajado con las distintas naciones indígenas en esta porción del continente.

Los Huarpes, dicen Techo y Ovalle, eran de talla muy elevada, delgados, de una ligereza extrema y de una resistencia extraordinaria; cazaban al ñandú persiguiéndole á pie durante un día ó dos sin detenerse hasta que el animal muerto de fatiga se dejaba apresar. Los Tobas, dice fray Zacarías Ducci, cazaban ciervos, gamos, jabalís, pecarís, nutrias, ñandús; tiene olfato y vista finísimos, son siempre los primeros en advertir un grito lejando ó un ruido cualquiera, los primeros en advertir un animal ú hombre que viene lejos (Correa Morales, 1910a: 548).

20 A través de la enumeración de los distintos pueblos cazadores Correa Morales da cuenta de la diversidad de pueblos indígenas que habitan en esta porción del continente. Las llamadas sociedades primitivas, son presentadas como pueblos de inteligencia inferior, pero de inmensa sensibilidad, la valentía de algunos grupos como los calchaquíes al momento de la llegada hispánica en el siglo XVII, los situaba desde su punto de vista como los primeros y legítimos ocupantes del territorio argentino (Correa Morales, 1911a: 21-23). Sin embargo, la extinción de estos diversos grupos parecería como un camino inevitable, quizás como resultado de aquello que desde su pensamiento podría pensarse como parte de un proceso evolutivo que, en este caso, se ligaba al "progreso económico", al "proceso civilizatorio" y al "proceso de blanqueamiento" presentado acríticamente por Elina de Correa Morales. Así, por lo menos lo expresa en una de las lecturas correspondiente al manual escolar Isipós, libro de cuentos para niños:

Donde en otro tiempo se levantaban sus tolderías se ven hoy colonias agrícolas, la pampa, que trepidaba otrora bajo el casco de los potros indios, trepida hoy bajo las ruedas de la locomotora (Correa Morales, 1911a: 213-214).

21 En este contexto, el problema que planteaba Correa Morales era el mismo que preocupaba a ciertos intelectuales de corte nacionalista como Joaquín V. González (Svampa, 1994: 89). Se trataba de ver por qué medios podría asegurarse la incorporación de la diversidad cultural ofrecida por los primitivos habitantes de aquello que en ese entonces se consideraba el territorio argentino, que en poco tiempo se transformaría en un rasgo del pasado y que en este período comenzaba a ser vista como un elemento que podía enriquecer a la invención de la tradición, en términos de Hobsbawn, en proceso de formación.

Una de las formas encontradas por Correa Morales para conformar esta tradición es la divulgación de las visiones de estos pueblos en los libros de lectura de colegios. En Isipós, por ejemplo, Correa Morales difunde la propia interpretación de las cosmogonías de las sociedades primitivas, donde naturaleza y cultura conforman una unidad indisociable y explican las formas de vida, los ritmos, los tiempos y los espacios.

Ahora bien, desde un punto de vista estrictamente académico, dos trabajos de Correa Morales se ocupan de la problemática de preservar los rasgos de las culturas pasadas. Uno se refiere a la cuestión de la toponimia y se denomina Nomenclatura Geográfica Argentina. En el mismo Correa Morales se muestra proclive a mantener las formas de denominación primaria de los diferentes accidentes geográficos ya que, su sustitución 
por otros como ha sucedido en el caso de algunos partidos o departamentos, significan la posibilidad de barrer con las memorias locales.

En cuanto a los nombres de partidos o departamentos de una provincia están estos por lo general demasiado ligados a las tradiciones e historia particular, cuando no a la general para que el cambio pueda ser considerado sin consecuencias; ya perdido el recuerdo de tales transformaciones onomásticas arbitrarias e inútiles, se verán en grandes apuros los maestros (de los cuales no podemos exigir sean especialistas en Historia y Geografía) para correlacionar la enseñanza de ambas; lo mismo puede decirse de la Etnología, donde cada nombre primitivo tiene para el sabio el valor de una piedra preciosa (Correa Morales, 1911b: 165).

El énfasis aquí es puesto en la importancia del mantenimiento de las toponimias primitivas. La relación entre el pasado y el presente que estas nomenclaturas reflejarían, facilitarían las tareas de los maestros que al enseñar Historia y Geografía, debían dar cuenta de ambos momentos. Ya el etnólogo encontraría en la conservación de los nombres que las sociedades primitivas daban a algunos lugares, una manera de reconstruir los significados de ciertos ámbitos de aquellas culturas.

En el segundo estudio denominado Notas breves sobre el arte geográfico y etnográfico, publicado en los Anales de GAEA en 1925, Correa Morales otorga importancia a las expresiones artísticas como mediaciones que, a través de las representaciones de los paisajes y los grupos étnicos del pasado, hacen su contribución a la construcción de la historia, de la geografía y de la cultura nacional.

Si se considera que el aspecto de la naturaleza se transforma rápidamente tanto por causas naturales como por influencias humanas, que los tipos étnicos puros han desaparecido casi por completo y que los mestizos han de borrarse también en la ola envolvente de la inmigración, podrá comprenderse cuán grande será, dentro de algunos siglos, el valor de las obras que los representan en su estado actual (Correa Morales, 1925: 224. El destacado es nuestro).

Las obras de arte entonces, son expresiones que permiten incorporan las herencias culturales del pasado a la tradición y componer la comunidad imaginada argentina del novecientos. Las pinturas de su maestro Della Valle o las esculturas de su marido Lucio Correa Morales son útiles en tanto representaciones de los que ella denomina "tipos nacionales" como el gaucho o el indígena. Ellas permitirán conocer en el futuro sus rasgos, su relación con el medio y sus modos de vida. Ellas transmitirán al futuro la diversidad cultural con la que contó el territorio argentino.

Pero, como vimos, Correa Morales, le otorga a la representación pictórica no sólo importancia desde el punto de vista de la preservación del modo de vida de los gauchos o de los indígenas, sino también de los propios paisajes. Ella considera que los procesos asociados al progreso, como la incorporación de tierras a la actividad agrícola, o la extensión del ferrocarril, modificarán tanto las formas naturales como las culturales.

De esta manera, podría afirmarse que a partir de estos abordajes Correa Morales recrea y resignifica algunos de las ideas de Joaquín V. González volcadas en Mis Montañas, obra que reivindica el interior, "como el lugar originario donde la identidad del argentino hallaba sus fuentes más arcanas” (Svampa, 1994: 90). En este texto, la tradición es un proyecto en realización conformado a partir de la descripción de sus paisajes y sus culturas entendida en términos de sus leyes, religión, poemas e historia frente a la amenaza de lo exótico. En el plan particular de Correa Morales la constitución de la comunidad imaginada argentina incorporaba particularmente las culturas de las sociedades primitivas y los paisajes pasados. Paradójicamente, estos aspectos naturales 
y culturales encontraban en las formas artísticas un vehículo para penetrar desde la tradición inventada en la nueva sociedad argentina que en nombre del "inevitable avance de la civilización y progreso" había arrasado con ellos. Como el ave fénix, ellos precisaron de su destrucción para emerger, aunque como estereotipos, en la Argentina de inicios del siglo XX.

\section{I.2 - La Geografía y su cientificidad} análisis de una porción de la realidad, Correa Morales se encuentra en la misma dificultad que muchos de sus colegas nacionales y extranjeros: la de definir objetos puros que sean de interés para el saber geográfico $\mathrm{y}$, a partir de allí, su especificidad. Pero la salida a esta problemática quiebra con los canones epistemológicos vigentes y muchos, entre ellos nuestra profesora normal, abogan tanto por la impureza de las preocupaciones disciplinarias como por la excepcionalidad del conocimiento geográfico. Correa Morales sigue al geógrafo británico Hugh Robert Mill, uno de los partidarios de situar a la Geografía en el campo de las ciencias y no de las letras y desde aquí reformular su enseñanza, para afirmar que:

En el campo de los conocimientos humanos, la Geografía ocupa una posición única y particular (...) Eslabón que une las ciencias con las letras, ella es el foco al cual convergen los rayos de las Ciencias Naturales, Historia y Economía (Correa Morales, 1904:149-150. El destacado es nuestro).

A partir de otorgarle a la Geografía un carácter sui generis, Correa Morales define la mirada que dirige sobre aquellos objetos que, en principio, no serían solo naturales o solo humanos. Esta intelectual adhiere a la posición según la cual el objeto de la Geografía sería el estudio de las nexosituaciones. Esta postura habría sido formulada por el geólogo catalán Huguet del Villar, continuada primero por Felix Outes (Barros, 2000) y presentada por el geólogo Juan Keidel en su conferencia inaugural del primer encuentro de Geografía de 1931. Así, Correa Morales en la introducción a la Geografía de la Argentina afirma:

En la primera Reunión Nacional de Geografía el doctor Juan Keidel (...) explica con toda claridad el concepto de situación, respecto del cual dice: "Dicho concepto no puede indicar un paraje casual, sin relaciones intrínsecas, sino una localización que esté determinada por circunstancias persistentes o dadas en un período de tiempo prolongado. Pensemos primero, en circunstancias establecidas por la misma naturaleza: pero lo mismo podemos tomar en cuenta situaciones que crea el hombre, siempre que ellas dependan de circunstancias naturales" y termina, "La situación de los objetos y procesos, determinada por circunstancias naturales recibe el nombre de nexosituación. Es la situación geográfica en el sentido propio de la palabra" (Correa Morales, 1947: 41-42. El destacado es nuestro).

31 En síntesis, mientras que la especificidad de los estudios geográficos residiría en el análisis de la localización, las particularidades de dicha localización estarían dadas por la peculiar manera en que se daría en dicho sitio la interrelación entre sociedad y naturaleza. Pero, en realidad, desde el punto de vista de Keidel, perspectiva respaldada por Correa Morales, la influencia de la naturaleza tiene un mayor peso que los "objetos y procesos" en las especificidades que adquiere dicha localización. Es la preeminencia del mundo natural sobre el de los hombres que la llevaría a deducir que la geografía física debería actuar de pilar sobre el cual se apoyarían el resto de los conocimientos geográficos. 
(...) todos los geógrafos sin excepción opinan que sin Geografía Física no hay geografía posible (...)puesto que si esta buena base falta, el edificio careciendo de estabilidad fácilmente se derrumba (Correa Morales,1947:155). Geografía que impulsó Joaquín V González desde el Ministerio de Justicia e Instrucción Pública (1904-1906). Esta propuesta estaba altamente influenciada por la escuela británica, particularmente por las visiones del ya mencionado Hugh Robert Mill con su obra The Realm of Nature; an Outline of Physiography; de A. J. Herbertson y su texto Man and his works; de Hinman, Ecletic Phisical Geography, o Redway con su libro New basis of Geography. Todos estos textos consideran a la Geografía Física la base de la enseñanza de la geografía en la escuela, motivo por el cual el Ministerio de Justicia e Instrucción Pública recomienda la formación de una Biblioteca Técnica a partir de su traducción (Quintero Palacios, 1999:156). Una manera de hacer que la enseñanza de estos contenidos fuese adecuada a los requerimientos nacionales era recomendar que su utilización fuese acompañada de aquellos trabajos realizados por viajeros y naturalistas, argentinos y extranjeros que habían contribuido al conocimiento del territorio argentino tales como: D' Orbigny, Darwin, Martin de Maussy, G. Burmeister, Brackebush, Holmberg, Ambrosetti, Moreno, Doering (Correa Morales, 1904:175). elabora un diagnóstico donde evalúa la posición y los contenidos de la Geografía en el ámbito de la escuela secundaria. En este nivel de enseñanza la disciplina, en general, era impartida por profesores provenientes del campo de la historia y de las letras y no de las ciencias naturales. Desde su punto de vista estos carecían de una formación adecuada para llevar los conocimientos de las ciencias naturales al ámbito del aula. Otorgarle un perfil naturalista a la Geografía era, para la autora, la única posibilidad de que dicha disciplina perdiera el supuesto carácter enciclopédico hegemónico en su enseñanza.

(...) los programas de Ciencias Físico-Naturales (...) forman la más poderosa palanca de la ciencia Geográfica , pues sólo una vinculación sistemática e inteligente entre esta y sus cooperadoras o concurrentes puede dar a los profesores la necesaria preparación para dictar buenos cursos de Geografía(Correa Morales, 1909: 169).

De esta manera, su proyecto disciplinario distanciaba la Geografía de las Humanidades, vinculación que, según su perspectiva, habría ligado a la disciplina a una propuesta "arcaica" que habría sido "fatal" para el desarrollo de este saber (Correa Morales, E. 1909: 170, 174, 175).

Para subsanar el alejamiento de la Geografía del campo de las ciencias naturales E. Correa Morales plantea una estrategia institucional destinada a modificar desde la formación del profesor de Geografía hasta los propios contenidos impartidos en la enseñanza. 


\section{II - El legado institucional y disciplinario de Elina Correa de Morales: La fundación de la Sociedad Argentina de Estudios Geográficos}

37 Toda tentativa de aproximarse al proceso de institucionalización, autonomización temática y metodológica de la Geografía, encuentra uno de sus primeros antecedentes históricos en la formación de Sociedades Geográficas. En la tarea de definir el perfil de estas instituciones, algunos estudios de la historia de la geografía distinguen aquellas Sociedades cuya formación puede situarse genéricamente en el siglo XIX y que aparecen, en primera instancia, como centros eminentemente culturales, que agrupan a "exploradores" y "aficionados" orientados por el interés de conocer aquellos territorios desconocidos y no apropiados por Occidente de aquellas otras asociaciones, conformadas hacia inicios del siglo $\mathrm{XX}$, que persiguen por sobre todo objetivos corporativos. En el caso de estas últimas, sus actividades tienen como centro de interés la formación y el perfeccionamiento del personal docente (Capel, 1977).

Sería posible afirmar que la Sociedad de Estudios Geográficos (GAEA) transitó y fue partícipe del pasaje entre estos dos modelos de Sociedades Geográficas. En sus inicios ella actuó como un ámbito cultural que agrupó a todos aquellos especialistas que estaban participando en los procesos de relevamiento y sistematización del conocimiento del territorio del país, tanto en sus aspectos físicos, etnográficos como económicos y políticos. Luego, a partir de su vínculo con la enseñanza y, particularmente, con el Ministerio de Educación, esta institución fue transformándose en un espacio que comenzó a nuclear a profesores de enseñanza, modelo que acaba perfilarse en los años 1945 durante la gestión de Federico Daus.

39 Esta Institución puede ser considerada como la sustanciación más relevante del proyecto disciplinario de Elina Correa Morales, en la medida que ella fue su fundadora en 1922 y presidenta hasta su muerte en 1942. Su gestión frente a la Sociedad permitió el inicio de este proceso de transformación ya que favoreció los vínculos de la Sociedad con el Ministerio de Educación durante el Gobierno de Alvear y convirtió a GAEA en la voz oficial de la Geografía Argentina. Como ya hemos visto, fue el interés de esta Sociedad Geográfica por estimular la incorporación del modelo científico de Geografía en la enseñanza secundaria, con raigambre en las ciencias naturales, lo que favoreció las relaciones entre dicha institución privada y el ámbito público de ingerencia directa en el proyecto educativo nacional (Zusman, 1996).

\section{II.1 - La fundación de la Sociedad Argentina de Estudios Geográficos}

Elina Correa Morales convocó para la formación de una Sociedad Geográfica a especialistas vinculados a diversas disciplinas y que, desde estos distintos saberes estaban contribuyendo, por un lado, al conocimiento territorial del país, y, por el otro, a proveer un cuerpo al saber geográfico bajo la propuesta epistemológica de carácter naturalista. La ausencia de historiadores, por ejemplo, podría confirmar este perfil. La convocatoria tuvo lugar en un ámbito donde la investigación en ciencias naturales ocupaban un lugar privilegiado tal como era la Sala de Botánica de la Facultad de Ciencias Exactas, Físicas y Naturales. Respondieron a su llamado algunos geólogos como 
Walter Schiller, y Juan José Nágera; naturalistas como Carlos Ameghino (en ese momento, director del Museo de Ciencias Naturales de Buenos Aires); cartógrafos como Guillermo Schultz y Juan Serie; profesores de geografía como Berta Wernicke, profesora de Escuela Normal, y Pascual Guaglianone, Inspector General de la gestión de Antonio Sagarna en el ministerio de Educación; antropólogos como Roberto Lehman Nitsche, su mujer Juliana Dillenius y Francisco Aparicio. En síntesis, un conjunto de especialistas nacionales ${ }^{2}$ y extranjeros ${ }^{3}$ se reunieron para conformar una Sociedad que "se ocupara con autoridad suficiente del estudio de la Geografía General en sus variadas disciplinas" (GAEA 1924). Parecería que estos especialistas aceptaran el carácter sui generis de la disciplina, a partir de entender que sus diversos aportes podrían contribuir a definir sus contenidos específicos.

41 Según rezan los estatutos, tres objetivos orientarían sus actividades. En primer lugar, esta Institución buscaba promover el conocimiento territorial a partir de encargarse de organizar exploraciones y excursiones o incentivar su realización por parte de otras entidades, particularmente a aquellas áreas no incorporadas al proyecto estatal nacional. Este tipo de objetivos la aproximaban y la hacían continuadora de las tareas llevadas adelante por las sociedades geográficas formadas en el siglo XIX en Europa, en general, y en Argentina, en particular. En segundo lugar, GAEA se planteaba como propósito la sistematización y difusión del conocimiento geográfico producido en relación al territorio a partir de traducir los trabajos referentes a la Geografía argentina dispersos en revistas extranjeras. En tercero y último lugar, ella deseaba efectuar gestiones para la instauración del proyecto disciplinario de inspiración naturalista en la enseñanza por distintos medios, sea a través de publicaciones propias, sea a través de presentaciones públicas académicas como podría ser la realización de conferencias o estrictamente políticas como podría ser la actuación ante los poderes públicos. En este marco se contemplaba también la creación de nuevos ámbitos institucionales para la geografía como lo habrían hecho Inglaterra, Francia, Austria, tales como una Escuela de Geografía o nuevas cátedras de geografía en las Universidades.

\section{II.2 - GAEA y el proyecto de difusión del conocimiento del territorio argentino}

Conforme a estos propósitos, GAEA se define, como una institución científica a través de la señalización de una serie de prácticas que llevaría adelante (reconocimientos territoriales, publicaciones, entre otras). Estas prácticas la posesionaban a la par de las instituciones que promocionaban disciplinas cuyo reconocimiento científico estaba socialmente garantizado.

Además, las tareas de promoción del reconocimiento territorial y de la enseñanza, conforme al proyecto disciplinario de corte naturalista, la colocaban en una situación adecuada para afirmar que esta institución científica estaba contribuyendo al conocimiento y difusión de las características físicas, económicas y etnográficas argentinas, sustento de la nacionalidad.

Cabe recordar también que, el interés de producir un conocimiento sobre el territorio argentino a cargo de científicos argentinos acompañaba los objetivos políticos del período, donde la visión civilizatoria se fundamentaba en un proyecto de carácter nacional, quizás menos eurocéntrica que aquella que habría sustentado la propuesta de formación del Estado Argentino. 

contexto donde, como ya vimos, desde la educación se acentuó la preocupación por socializar a los habitantes del país en los considerados valores nacionales llevaron a E. Correa Morales a interesarse por proponer la difusión de este tipo de proyecto en el marco educativo.

En Isondú, otro libro de lectura para cuarto grado que Correa Morales publica en 1901, aparecen fragmentos de obras de literatos nacionales y extranjeros, de naturalistas y también algunos textos propios. Uno de estos fragmentos se refiere a la cuestión del patriotismo. En el mismo la autora invita a los habitantes del país, en este caso los alumnos, a sentirse partícipe de la construcción del proyecto nacional estatal a partir del dominio de una profesión. Correa Morales busca crear un compromiso colectivo rompiendo con lo que ella considera como el significado estrecho del término patriotismo:

(...) para la generalidad, sólo es patriota el soldado que defiende la patria; el jefe que obtiene una brillante victoria; el gobernante que se distingue por la honorabilidad de sus procederes, nadie recuerda que hay patriotismo en el maestro abnegado que prepara varias generaciones de ciudadanos; (...) en el artista y en el escritor que ponen al servicio del arte y de la ciencia toda la sinceridad de su alma, todo el poder de su inteligencia (Correa Morales,1901:107. El destacado es nuestro).

De esta manera, Correa Morales, busca comprometer en la construcción de lo que ella denomina la patria no sólo a aquellos actores directamente partícipes en el proyecto político (el gobernante) sino también a los representantes de los sectores civiles (artistas, escritores, médicos) y en donde también incluye a todo tipo de asociaciones:

Cada país es una inmensa maquinaria, cuyas ruedas están formadas por agrupaciones, que ya como empresas industriales, ya como sociedades científicas, artísticas, literarias o de caridad, tratan de llevar a buen término el fin que se han propuesto; en cada una de estas agrupaciones se destacan algunas figuras culminantes que buscan no sólo el provecho práctico sino la realización de un ideal, el cual con frecuencia consiste en dotar a un país de aquello que le falta para ponerlo al nivel de los estados más prósperos; eso, cualquiera que sea la forma en que se manifieste, se llama patriotismo (Correa Morales, 1901:108. El destacado es nuestro).

De acuerdo a lo expresado aquí, entonces, ser patriota es comprometerse con un deber de carácter cívico que consiste en situar al país "entre los estados más prósperos", ya sea a través de acciones individuales o a través de prácticas colectivas. En este aspecto Correa de Morales comparte la visión del progreso generalizada en el proyecto de formación estatal decimonónico y con el cual no rompen los grupos gobernantes y las elites intelectuales de inicios del siglo XX. Según esta visión, Argentina era un país atrasado, que se encontraba en condiciones alcanzar la civilización (europea), que el progreso en estos términos era posible y que, en el camino para alcanzarlo, el dominio del conocimiento en sus diferentes variantes artístico, literario o técnico jugaba un papel importante. A través de su destaque en cada una de estas especialidades los sujetos o las sociedades que los agrupen serán patriotas, entendiendo por patriota, ahora, en un sentido amplio: "todo ciudadano que contribuya de algún modo a la florescencia de su país" (Correa Morales, 1901: 108).

Pero, en 1910, en el artículo que Elina Correa Morales escribe en ocasión de celebrase el aniversario del centenario de la Revolución de Mayo, denominado Progresos Geográficos en la República Argentina, un número especial conmemorativo del diario la Nación, ella muestra que la Geografía ya estaba haciendo sus contribuciones en este sentido, aún 
cuando quedaba mucha tarea por delante. Siguiendo su concepción de alta imbricación entre Historia de la Geografía y Geografía Histórica, Correa Morales confunde el reconocimiento material del territorio con el desenvolvimiento del conocimiento geográfico que, desde su punto de vista, se sitúa entre los saberes científicos que más han "progresado" entre la segunda mitad del siglo XIX y la primera década del XX en Argentina.

En este discurso Correa Morales incentiva a los científicos de la época a emprender el reconocimiento de áreas aún no exploradas del territorio argentino:

El estudio de los ventisqueros ni siquiera está iniciado; la extensión de lagos y ríos prehistóricos, los canales que atravesaron la Patagonia y Tierra del Fuego y mil problemas relacionados no sólo con la paleografía, sino con la geografía económica, penden de estudios sistemáticos (Correa Morales, 1910:170).

Y parafraseando a Francisco Villarino, ${ }^{4}$ piloto español que, bajo órdenes de la Corte Española exploró el río Colorado en siglo XVIII, Correa Morales afirma:

(...) sería deplorable (...) que los extranjeros vinieran a enseñar los rincones de su propia casa (...).Esperemos que el adelanto de las ciencias y las grandes facilidades que para su estudio tiene hoy aqui, despierte entre nosotros el deseo de abordar tan hermoso problema geográfico que espera solución (Correa Morales, 1910:170).

En síntesis, a partir de un libro de texto como era Isondú Correa Morales buscaba difundir en las futuras generaciones la creencia que el trabajo destinado a superar el supuesto atraso que vivenciaba la Argentina contribuiría al florecimiento del país. Esta era una "misión patriótica" en el sentido amplio del concepto. En el artículo aparecido en el diario La Nación, Elina Correa de Morales sostiene que los científicos argentinos y particularmente aquellos especializados en el reconocimiento de las características físicas, etnográficas y económicas del territorio ya estaban cumpliendo con dicha "misión patriótica", una tarea que, vista desde este punto de vista trasciende la propia actividad ya que contribuye al desarrollo de "un sentimiento de identificación grupal de un pueblo con su ámbito territorial (naturalizado) de pertenencia legítima" (Escolar, Quintero Palacios, Reboratti, 1994: 355).

53 Ahora bien, para Correa Morales, el aporte a la superación del atraso del país en términos de conocimientos territoriales no tendría que quedar sólo en manos de los sujetos individualmente sino también podría ser promovida por Sociedades Científicas, como lo expresa en el texto de Isondú. Esto quiere decir que, a través de la promoción de un proyecto disciplinario de base cientificista GAEA contribuiría al conocimiento "riguroso" y "preciso" del territorio, tarea que sería una muestra del espíritu patriótico de la Sociedad Argentina de Estudios Geográficos, de su fundadora Elina Correa De Morales y de todos los otros especialistas que participan de las actividades de esta institución. Se trata de un objetivo que si bien no se hace explícito en sus estatutos, orienta la creación de la Institución.

\section{II.3 - Llevando la propuesta a los ámbitos de enseñanza}

En la gestión del Ministro de Justicia y Instrucción Pública del Gobierno de Alvear, Antonio Sagarna (1922-1928), fueron realizadas importantes reformas en los planes de estudios de enseñanza secundaria. A través de las mismas se buscaba modernizar y otorgar un carácter científico tanto a los contenidos como a los métodos utilizados. En esta gestión dos miembros de GAEA participaron activamente en esta propuesta reformadora. Eran ellos Pascual Guaglianone, Inspector General de Escuelas, y Juan 
Nágera quienes, a través de su actuación, buscaron llevar el proyecto epistemológico de corte naturalista al campo de la enseñanza de la geografía. La reformulación educativa provocó la reacción de los profesores de geografía, en su mayoría formados en abogacía, profesores normales y universitarios recibidos en historia o letras, o simplemente aficionados sin formación institucional que seguían la propuesta disciplinaria más próxima al campo de las letras que al de las ciencias naturales. Los profesores de enseñanza media argumentaban que los nuevos programas poseían un fuerte carácter cientificista, que estaban orientados esencialmente al área natural, llenos de neologismos provenientes de la geología y de la geografía física, los cuales no podían ser suficientemente comprendidos por los responsables de las clases en los niveles primario y secundario. Por su lado, los formuladores de la propuesta renovadora justificaban las reformas en la necesidad de dejar de lado el modelo descriptivo de geografía para sustituirlo por un conocimiento fundamentado en la combinación de leyes físicas y naturales, en la tradición disciplinar de Huxley, De Martonne, Huguet de Villar y Ratzel (Cámara de Diputados de la Nación, 1926).

La fuerza de la confrontación llevó al propio Ministerio a recurrir a la propia Sociedad de Estudios Geográficos para que esta emitiera su parecer referente a los programas implementados. La comisión que emprendió esta tarea acaba felicitando a la gestión ministerial por los cambios llevados a cabo, utilizando las siguientes palabras:

(...) esos programas representan un progreso en el estudio de la Geografía, pues, quitándole el carácter esencialmente enumerativo y memorista que tenía, los lleva al terreno de las Ciencias Naturales y por ende al del laboratorio, incluyendo en esta designación el estudio sobre el terreno del mismo. Considerada la Geografía en esta forma, la Argentina sigue la orientación impresa hace décadas por las naciones más adelantada, y por geógrafos de la talla de Penck en Alemania, Martonne en Francia, Salisbury en Estados Unidos, Rozier en Suiza, Markham en Inglaterra, etc. (GAEA, 1926-1927: 493).

Difícil era no concordar con esta propuesta disciplinaria cuando eran los propios miembros de esta Sociedad que participaron en la formulación de los programas curriculares, legitimadas científicamente por situarse entre las propuestas más modernas desarrolladas en Europa.

Muchos de los participantes en esta comisión fueron convocados posteriormente para la realización de una tarea que también agitó al ámbito educativo: la revisión de los textos para la enseñanza. La Comisión estuvo presidida por Elina Correa Morales y contó entre sus miembros con el profesor de geografía Romualdo Ardissone; el maestro normal Juan W. Gez; los geólogos Pablo Groeber, Joaquin Frenguelli y Juan Keidel; el botánico Cristobal M. Hicken; el cartógrafo Augusto Tapia y el zoólogo Anselmo Windhausen (GAEA, 1926-1927: 485).

Dicha comisión tenía por propósito evaluar la posibilidad de que estos libros se adecuaran a las reformas establecidas en los programas. De los cincuenta y tres textos revisados, ninguno se adaptaba a los nuevos programas y sólo dieciséis de ellos fueron considerados sólo de "utilidad como libros de consulta" (Cámara de Diputados, 1927). La inadecuación se fundamentaba en que las temáticas abordadas no se correspondían con las propuestas por los nuevos planes. Por ejemplo, el libro de geografía de Delfin Gijena, La naturaleza y el hombre, "trata solamente una parte de lo que exigen los programas". A esta inadecuación, se agregaron, en la mayoría de los pareceres, argumentaciones que señalaban "la desactualización de los datos y de los avances en los conocimientos territoriales" y "la carencia de mapas e ilustraciones". 

Juan G. Beltrán y Juan R. Beltrán, por ejemplo, era desaconsejado porque en el tratamiento de las cuestiones hidrográficas:

(...) falta un capítulo general donde se establezca la relación entre las precipitaciones y las redes hidrográficas con sus mapas correspondientes, procurando al mismo tiempo una clasificación racional y un estudio más científico" (Cámara de Diputados de la Nación, 1927: 334).

Otras veces, los "jueces de los libros de texto" justificaban la inadecuación de algunos textos en la falta de "carácter geográfico" o el "desconocimiento de las vertientes más modernas de la disciplina". A pesar de la valoración que se realizaba de las contribuciones internacionales recientes, los miembros de esta comisión consideraban que estos textos fundamentalmente debían contribuir a la formación de los valores nacionales. Por ejemplo, la misma obra de Juan G. Beltrán y Juan R. Beltrán era acusada de apenas tratar la cuestión minera. Ello, según los miembros de la comisión, donde participaban tres geólogos, atentaba a los objetivos formativos de la disciplina.

La juventud no debe ignorar su situación actual, a fin de que desaparezcan muchas ideas fantásticas muy comunes, y quede la convicción de que es necesario estudiar mucho el país, explorarlo mucho, para que esta rama de la actualidad argentina alcance alguna vez el desarrollo que le corresponde (Cámara de Diputados, 1927:334. Los destacados son nuestros).

61 Y es este interés por enfatizar el carácter nacionalizador de los contenidos geográficos que lleva a la comisión a desaconsejar como libro de texto aquellas elaboradas por los propios mentores internacionales del proyecto disciplinario como las obras de Vidal de la Blache o Huguet de Villar. Estas obras eran desaconsejadas como libro básicos para la enseñanza, aunque eran reservadas como libros de consulta.

Por ejemplo, según la Comisión evaluadora de los libros de textos, la Geografía General de Huguet de Villar era considerada un:

(...) trabajo editado en el extranjero, carece de referencias sobre nuestro país y cuando se trata de cuestiones geográficas en general, menester es el estudio especial sobre el mismo, falta que obliga al estudiante a adquirir otra obra (Cámara de Diputados, 1927:334).

63 Las acusaciones llevadas adelante por la comisión significaron un nuevo enfrentamiento entre las posturas de los profesores de la escuela secundaria, apoyadas ahora por algunas editoras, y los representantes de Geografía en el Ministerio de Educación.

64 El proyecto de GAEA de reformar los contenidos enseñados en Geografía no se limitó a los niveles primario y secundario. De acuerdo a sus objetivos fundacionales, en 1927 esta Sociedad elevó al Ministerio de Instrucción Pública la propuesta de crear un centro de altos estudios especializados en geografía, destinados a formar profesores en el área (Gez, 1928) proyecto que, finalmente, no se llevó adelante.

65 Como vimos, a lo largo de la gestión del Ministro Sagarna, crecen los vínculos entre GAEA y el Ministerio de Educación. Durante este período GAEA también contó con el apoyo financiero de dicho Ministerio para el desarrollo de varias de sus actividades como la confección de los mapas y gráficos del proyecto del libro de Geografía de la República Argentina (GAEA, 1928-29: 553). A manera de gratificación simbólica por el espacio con el cual esta Sociedad Geográfica llegó a contar en el Ministerio de Educación, Antonio Sagarna es nombrado socio honorario de dicha entidad. 

disciplinar nos permite inferir que, hacia finales de la década de 1920, GAEA se convirtió en la portavoz oficial de la Geografía a ser enseñada. La Geografía se habría convertido en un conocimiento valorizado en la escuela primaria y media por sus "atributos nacionalizadores", ahora a través de una propuesta de base naturalista. A partir de esta estrategia epistemológica se buscaba que la geografía ganará el "status de conocimiento verdadero", un conocimiento legítimo acerca del territorio (Escolar, 1996). Es entonces quizás en una propuesta de esta índole que debemos buscar los orígenes de la difusión y generalización de una visión naturalizada de la sociedad y del territorio vehiculizada a través de los curriculum de la escuela primaria y media.

\section{III - Naturaleza y tradición en los orígenes de la Geografía Nacional}

67 A esta altura del análisis podemos afirmar que la producción de Elina Correa Morales trasluce, en primer lugar, su adhesión al proyecto decimonónico de incorporar al país al ámbito internacional desde un proyecto científico cultural. Desde esta autora las ideas de "civilización y progreso" sí eran traducibles al campo del conocimiento científico, a partir de articular la ciencia y la cultura a los estándares vigentes a nivel internacional, con las especificidades que la propia producción en tanto relevamiento de los rasgos físicos y culturales del territorio argentino podría ofrecer.

Sin embargo, a pesar de ser heredera del espíritu vigente hacia finales del siglo XIX en el proyecto de formación del Estado Argentino, este es recreado de acuerdo a las necesidades vivenciadas en los novecientos. Un país que había crecido demográficamente con los aportes migratorios europeos, y que ahora ve en él una amenaza que pone en cuestión el modelo de Estado-Nación instituido, requería la urgente socialización de sus nuevos habitantes en los valores de la clase dirigente del nuevo siglo. Esta socialización debería realizarse no ya bajo una propuesta cosmopolita sino a partir de resignificar aquellos aspectos culturales representantes de lo propio y lo nativo hasta entonces descalificados por considerarlos, en términos de Sarmiento, ${ }^{5}$ símbolos de la barbarie. En este nuevo contexto nacionalista las posturas de Correa Morales la aproximan política e intelectualmente a las visiones tanto de las corrientes espiritualistas como positivistas de inicios de siglo $\mathrm{y}$, particularmente, a las concepciones de Joaquín V. González.

En primer lugar, Correa Morales, al igual que González, considera de importancia el proceso de "invención de la tradición" como tarea que significa crear un pasado cultural y geográfico particular con el cual se sientan identificados los habitantes de la Argentina. Esta autora tematiza esta preocupación en algunos estudios de tipo antropológico y geográfico. Desde su perspectiva, paisajes y sociedades primitivas desvastadas en el marco de ingreso del país al capitalismo mundial, pasan a integrar dicha tradición.

70 En segundo lugar, y ya desde un punto de vista estrictamente disciplinario, Correa Morales adhiere no sólo carácter nacionalizador que Joaquín V. González atribuía a la Geografía en la enseñanza sino también a un proyecto epistemológico naturalista hegemónico en las diversas escuelas europeas (Berdoulay, Soubeyran, 1981; Archer, 1993). Desde su gestión en el Ministerio de Instrucción Pública Joaquín V. González

Terra Brasilis, 3 | 2001 
impulsó que la disciplina pusiese el énfasis en la enseñanza de la Geografía Física. Esta postura situaría a la Geografía Nacional al nivel de la Geografía Internacional. A pesar de la importancia otorgada al seguimiento de las posturas cientificistas, su carácter nacionalizador sólo sería asegurado por incorporar aquellos conocimientos que diesen cuenta de los avances realizados en el conocimiento del territorio argentino.

71 Entre la construcción de la tradición y la difusión de una imagen del territorio desde la perspectiva naturalista, ambos consideran que los contenidos nacionalistas que Geografía debía impartir a nivel primario enfatizarían el primer aspecto, mientras que en la enseñanza secundaria donde la geografía contaba con un espacio propio, la aproximación al conocimiento del territorio debía realizarse sobre la base del conocimiento científico. Sin otra mediación didáctica que resaltar la experiencia cotidiana y la observación directa, los contenidos geográficos producidos a nivel académico podían ser traspuestos con fines educativos.

La propuesta de naturalización del conocimiento geográfico, no significó escindir el campo de la geografía del de la cultura. Se trató de una estrategia de autonomización académica y legitimación científica que Elina Correa Morales lideró desde la Sociedad Argentina de Estudios Geográficos pero, que para la época, no significó un alejamiento de las propuestas que se estaban discutiendo en otros ámbitos disciplinarios que se interesaban más por dar cuenta de los aspectos culturales. En primer lugar porque las áreas que se aproximaban al estudio de otras culturas también estaban sometidas a los encantos del cientificismo en sus versiones evolucionistas y, en segundo lugar, porque la propia trayectoria de Correa Morales muestra la no escisión entre espacios científicos y espacios culturales. Quizás las causas de la perduración de la propuesta naturalista y sus consecuencias ontológicas no deban buscarse en el propio momento histórico de aquellos que la formularon sino en el de aquellos otros que, por un lado, sí buscaron diferenciar de forma más marcada el campo de las ciencias naturales de las ciencias sociales y que, a pesar del desarrollo alcanzado en estas últimas en términos teórico-metodológico tendientes a adquirir una perspectiva que se adecuara más a los comportamientos humanos (corrientes comprensivistas, historicistas o etnográficas, para citar algunas), siguieron estudiando los sujetos, las regiones y los territorios como organismos con autonomía desligados de todo tipo de ideario o proyecto político.

APOLONIA DEL BRUTTO, B. (1998). Mujeres sindicalistas en la República Argentina. http/ www1.ldc.lu.se/latinam/virtual/mujer/apolonia.htm.

\section{BIBLIOGRAFÍA}

ARCHER, K. (1993). "Regions as Social Organisms: The Lamarckian Characteristics of Vidal de la Blache's Regional Geography” in Annals of Association of American Geographers, 83 (3).

Barrancos, D. (2000). "Itinerarios científicos femeninos a principios del siglo XX" in Montserrat, M. (comp.). La ciencia en la Argentina entre siglos. Textos, contextos e instituciones. Buenos Aires, Manantial. 
BARROS, C. (2000). De culturas a territorios. La antropogeografía en Buenos Aires. El proyecto académico de Félix Outes en los inicios del Siglo XX. Tesis de Maestría en Estudios Ambientales y Territoriales. Facultad de Filosofía y Letras. Universidad de Buenos Aires, Buenos Aires.

BERDOULAY, V.; SOUBEYRAN, O. (1991) “Lamarck, Darwin et Vidal: aux fondements naturalistes de la géographie humaine" in Annales de Géographie n 561-562.

CAPEL, H. (1977). “Institucionalización de la geografía y estrategias de la comunidad científica de los geógrafos" in Geocrítica no 8 y 9.

CASAL, P. (1943). "Elina Gonzalez Acha de Correa Morales. Necrológica" in Anales GAEA Tomo VII.

ESCOLAR, M.(1996). “Um discurso 'legítimo’ sobre o território: Geografia e Ciências Sociais” in Crítica do Discurso Geográfico. São Paulo, Hucitec

ESCOLAR, M.; QUINTERO, S.; REBORATTI C. (1994). “Geography, Territorial identity and patriotic representation in Argentina." in HOOSON (ed). Geography and National Identity. Oxford, Blackwell. FOUCAULT, M. (1999). El orden del discurso. Barcelona, Tusquets.

FUNDACION FRANCISCO APARICIO (1977). Dos Semblanzas, dos bibliografías: Elina González Acha de Correa Morales, Francisco de Aparicio. Imprenta Buenos Aires, J. Fontana S.A.

GEZ, J.W.(1928). "Sociedad Argentina de Estudios Geográficos : GAEA" in Anales de la Sociedad Cientifica Argentina $n^{\circ} 106$ (2).

PUIGGRÓS, A. (1990). Sujetos, disciplina y curriculum en los orígenes del sistema educativo argentino. Buenos Aires, Editorial Galerna.

QUINTERO PALACIOS, S. (1999). "State promotion of Mackinder's New Geography ithe Argentina (1900-1910)" in Buttimer, A.; Brunn Stanley, D. Wardenga, U. Text and Image. Social Construction of Regional Knowledge. (eds). Beiträge zur Regionalen Geographie. № 49. Institue für Länderkunde, Leipzig.

ROIG, A. (1964). "El normalismo y el normalismo positivista en Mendoza" in Revista de Estudios Políticos $y$ Sociales $n^{\circ}$ XIII, Mendoza.

SVAMPA, M. (1994). El dilema argentino: civilización y barbarie. Buenos Aires, Ediciones El Cielo por Asalto.

WEISBRODE, K.; COLLEDGE, B.(1991). "Spiritual nationalism \& Politics in Argentina (1900-1912)" in Program in Latin America Studies. Occasional Paper.

SOCIETY OF WOMAN GEOGRAPHERS (2001). "Who we are”. http://www.iswg.org/

\section{ANEXOS}

ZUSMAN, P. (1996) “Una Geografía científica a ser enseñada la Sociedad Argentina de Estudios Geográficos” in Documents d'Anàlisi Geogràfica Nº 31. Departamento de Geografia. Universitat Autónoma de Barcelona.

\section{Fuentes}

CAMARA DE DIPUTADOS DE LA NACIÓN (1926). “Diario de Sesiones Antecedentes relativos a la aplicación de los nuevos programas de enseñanza secundaria". . (1927). "Diario de Sesiones. Dictámenes de las Comisiones sobre Textos de Geografía". 
CORREA MORALES, E. (1901). Isondú. Lecturas variadas para cuarto grado. Buenos Aires, Imp. Boletín Industrial.

. (1904). "La enseñanza de la Geografía" in BIGA Vol. XXI.

. (1908) Geografía Elemental. Primer Libro. Buenos Aires, Cabaut y Cia.

. (1909). “Enseñanza de la Geografía en la República Argentina. Su amplitud” in BIGA Vol. XXIII.

. (1910a). "Facultades que han contribuido a desarrollar el ejercicio de la caza entre los primitivos" in Actas del Congreso Internacional de Americanistas. Buenos Aires, Ed. Coni.

(1910b). "Progresos geográficos en la República Argentina." in La Nación.

Edición Conmemorativa del 100 aniversario de la Revolución de Mayo.

. (1911a). Isipós. Tradiciones y cuentos para niños. Buenos Aires, Boletín Industrial.

. (1911b). “Nomenclatura Geográfica Argentina”. in BIGA Vol. XXIII.

. (1925). "Notas breves sobre el arte geográfico y etnográfico” in Anales GAEA.

Tomo I.

. (1947). "Resumen histórico-geográfico" in GAEA. Geografía de la República

Argentina. V1.

IGA / INSTITUTO GEOGRÁFICO ARGENTINO (1889). “Actas de sesiones” in BIGA Tomo VI.

GAEA / SOCIEDAD ARGENTINA DE ESTUDIOS GEOGRAFICOS (1924). “Estatutos”. in BGAEA $n^{\circ} 1$.

. (1926-1927). “Los programas de Geografía” in Anales GAEA tomo II.

. (1928-1929). Anales GAEA tomo III.

\section{NOTAS}

1. La sigla GAEA no corresponde a las iniciales de la sociedad geográfica sino que hace alusión al término que en latín se utiliza para hacer referencia a la Tierra.

2. Participaron también en la fundación el escultor Lucio Correa Luna, Carlos Gallardo, Alfredo Kolliker y Raúl Pietranera.

3. Además de Roberto Lehman Nitsche y Guillermo Schultz fueron especialistas alemanes con activa colaboración en la institución Walter Schiller, Franz Kuhn y Juan Keidel.

4. Cabe destacar que el extranjero al que se estaba refiriendo Villarino pertenece a otro momento histórico de aquel que se refiere Correa Morales. Mientras el primero muestra el interés que otras potencias coloniales como Inglaterra o Francia tenían en la época colonial en los territorios patagónicos, Correa Morales se refiere a los científicos de Inglaterra o Alemania que habían realizado relevamientos del territorio argentino durante el proceso de formación del estado argentino, muchas veces contratados por el propio gobierno nacional.

5. Domingo Faustino Sarmiento (1811-88) fue uno de los intelectuales que participó ideológica y políticamente en el proyecto fundacional del Estado Nación Argentino. Escritor, educador y político, entre los años 1868-74 fue presidente del país. Su texto Civilización y barbarie. Vida de Juan Facundo Quiroga. Aspecto físico, costumbres, hábitos de la República Argentina, publicado en 1845, hace de la dicotomía civilización y barbarie el centro de su análisis. Mientras que vincula la idea de 
civilización a Europa, a la vida de ciudad, a Buenos Aires, la de barbarie es asociada con la del nativo americano, con el mundo rural y con el gaucho.

\section{ÍNDICE}

Índice geográfico: Argentina

Índice cronológico: 1861, 1942

\section{AUTOR}

\section{PERLA ZUSMAN}

Departamento de Geografía Universidad Autónoma de Barcelona. perlazusman@yahoo.es 